\title{
Upregulation of Relaxin after Experimental Subarachnoid Hemorrhage in Rabbits
}

\author{
Yuichiro Kikkawa, Satoshi Matsuo, Ryota Kurogi, Akira Nakamizo, \\ Masahiro Mizoguchi, and Tomio Sasaki \\ Department of Neurosurgery, Graduate School of Medical Sciences, Kyushu University, 3-1-1 Maidashi, \\ Higashi-ku, Fukuoka, Fukuoka 812-8582, Japan \\ Correspondence should be addressed to Yuichiro Kikkawa; ykikkawa@ns.med.kyushu-u.ac.jp
}

Received 9 March 2014; Accepted 24 June 2014; Published 16 July 2014

Academic Editor: Chih-Lung Lin

Copyright ( 2014 Yuichiro Kikkawa et al. This is an open access article distributed under the Creative Commons Attribution License, which permits unrestricted use, distribution, and reproduction in any medium, provided the original work is properly cited.

\begin{abstract}
Background. Although relaxin causes vasodilatation in systemic arteries, little is known about its role in cerebral arteries. We investigated the expression and role of relaxin in basilar arteries after subarachnoid hemorrhage (SAH) in rabbits. Methods. Microarray analysis with rabbit basilar artery RNA was performed. Messenger RNA expression of relaxin-1 and relaxin/insulinlike family peptide receptor 1 (RXFP1) was investigated with quantitative RT-PCR. RXFP1 expression in the basilar artery was investigated with immunohistochemistry. Relaxin concentrations in cerebrospinal fluid (CSF) and serum were investigated with an enzyme-linked immunosorbent assay. Using human brain vascular smooth muscle cells (HBVSMC) preincubated with relaxin, myosin light chain phosphorylation (MLC) was investigated with immunoblotting after endothelin-1 stimulation. Results. After SAH, RXFP1 mRNA and protein were significantly downregulated on day 3, whereas relaxin-1 mRNA was significantly upregulated on day 7. The relaxin concentration in CSF was significantly elevated on days 5 and 7. Pretreatment with relaxin reduced sustained MLC phosphorylation induced by endothelin-1 in HBVSMC. Conclusion. Upregulation of relaxin and downregulation of RXFP1 after SAH may participate in development of cerebral vasospasm. Downregulation of RXFP1 may induce a functional decrease in relaxin activity during vasospasm. Understanding the role of relaxin may provide further insight into the mechanisms of cerebral vasospasm.
\end{abstract}

\section{Introduction}

Cerebral vasospasm is one of the most important cerebrovascular events following subarachnoid hemorrhage (SAH) and is characterized by delayed and prolonged contraction of cerebral arteries that may cause cerebral ischemia and lead to death or neurological deficits in patients with SAH [1]. Therefore, the prevention as well as treatment of vasospasm is important in the management of SAH patients. Although increased production of spasmogens and increased vascular responsiveness can be attributed to cerebral vasospasm, the mechanism of cerebral vasospasm remains elusive, and thus effective therapeutic strategies are not available. Recent randomized clinical trials have shown that currently available antivasospastic drugs are not sufficient to improve outcome [2]. Therefore, further research efforts are needed to clarify the mechanism of vasospasm and find new therapeutic targets.

Relaxin is a small peptide hormone $(6 \mathrm{kDa})$ that is primarily produced by the corpus luteum, decidua, and placenta during pregnancy [3]. Three relaxin genes have been identified in humans and are designated as relaxin-1 ( $R L N 1)$, relaxin-2 (RLN2), and relaxin-3 (RLN3). Human relaxin-2 is the only form of circulating relaxin that is substantially increased during pregnancy [4]. Human relaxin-2 is functionally equivalent to relaxin-1 in all other mammals [5]. Recently, RLN mRNA expression has also been detected in nonreproductive tissues including arteries, heart, kidney, liver, and lung [6-8].

Four relaxin receptor genes have been identified. They are relaxin/insulin-like family peptide receptors and are named RXFP1 (RXFP1), RXFP2 (RXFP2), RXFP3 (RXFP3), and 
RXFP4 (RXFP4) [8]. Circulating relaxin (relaxin-2 in humans and relaxin-1 in other mammals) binds to PRXFP1 (previously known as leucine-rich repeat-containing G-proteincoupled receptor 7: LGR 7) with high affinity $[7,9,10]$. RXFP1 mRNA and protein are expressed in a wide range of reproductive tissues including ovary, uterus, placenta, mammary gland, prostate, and testis [8]. The receptor is also expressed in nonreproductive tissues including heart, kidney, lung, liver, and vasculature [8]. Beyond a role in the reproductive system during pregnancy, a growing body of literature suggests that relaxin has extensive cardiovascular effects such as promoting vasodilation and angiogenesis and protecting against fibrosis and inflammation in systemic and renal circulation $[11,12]$.

Several recent studies have reported that relaxin and RXFP1 (LGR7) are expressed in the local arteries of mice and rats $[13,14]$. These molecules are localized in the local arterial wall and seem to contribute to increased arterial compliance and reduced myogenic reactivity, and they may mediate blood flow to tissues [13, 14].

Based on the potent cardiovascular effects of relaxin, we hypothesize that relaxin dilates the cerebral arteries and plays a role in mediating cerebral blood flow. To date, however, no study has explored the expression and role of relaxin and its receptor, RXFP1, in the cerebral arteries after SAH. Therefore, the purpose of the present study was to investigate the time course of RLN and RXFP1 expression in the cerebral arteries after SAH and to clarify the role of relaxin during vasospasm.

\section{Materials and Methods}

2.1. Preparation of the Rabbit SAH Model. This study was performed in accordance with the guidelines for proper conduct of animal experiments published by the Science Council of Japan. The study protocol was approved by the Animal Care and Use Committee, Kyushu University (Permit number A24-103-0). Adult male Japanese white rabbits (2.5 to $3.0 \mathrm{~kg}$ ) were anesthetized with an intramuscular injection of ketamine ( $40 \mathrm{mg} / \mathrm{kg}$ body weight) and given an intravenous injection of sodium pentobarbital ( $20 \mathrm{mg} / \mathrm{kg}$ body weight). On day $0,0.5 \mathrm{~mL}$ cerebrospinal fluid (CSF) was aspirated percutaneously from the cisterna magna using a 23-gauge butterfly needle, and then $2.5 \mathrm{~mL}$ nonheparinized autologous arterial blood that was obtained from the central ear artery was injected into the cisterna magna over 1 minute. The animal was kept in a prone position with the head tilted down at $30^{\circ}$ for 30 minutes. During this procedure, no blood clot formation was observed in the syringe. On day 2, a similar second injection of autologous blood was performed. In this study, rabbits that did not undergo any surgical procedures including puncturing of skin or dura mater with a needle were used as control model (day 0 ). One of the reasons why nonmanipulated rabbit was used as the control model is to curb the number of rabbits used as possible from the point of view of animal ethics.

2.2. Harvest of Rabbit Basilar Artery. On days 0, 3, 5, and 7 after the first hemorrhage, the rabbits were heparinized (400 U/kg body weight), euthanized by intravenous injection of an overdose of sodium pentobarbital $(120 \mathrm{mg} / \mathrm{kg}$ body weight), and exsanguinated from the common carotid artery. Exposure of the brain revealed clot formation over the surface of the pons and the basilar artery in the SAH animals. Immediately after removing the whole brain en bloc, the subarachnoid membrane was carefully dissected, and the clot was gently removed under a binocular microscope (Leica EZ4D, Leica Microsystems, Wetzler, Germany) with microscissors and microforceps so as not to touch the basilar artery. The distal half of the surface of the basilar artery in particular was covered with a thick clot in all rabbits with SAH. To estimate vasospasm, the external diameter of the basilar artery was measured at a location that was onethird the length from the distal end of the basilar artery. The ventral surface of the whole brain was photographed with a digital camera (CX3, Richo, Tokyo, Japan), and the external diameter of the basilar artery was analyzed with ImageJ (National Institutes of Health, Bethesda, MD, USA). The entire length of the basilar artery was then immediately excised from the brain and dissected free from surrounding tissues with microscissors and microforceps. Intraluminal blood was gently hand-flushed out with normal physiological salt solution $(123 \mathrm{mmol} / \mathrm{L} \mathrm{NaCl}, 4.7 \mathrm{mmol} / \mathrm{L} \mathrm{KCl}$, $1.25 \mathrm{mmol} / \mathrm{L} \mathrm{CaCl}_{2}, 1.2 \mathrm{mmol} / \mathrm{L} \mathrm{MgCl}_{2}, 1.2 \mathrm{mmol} / \mathrm{L} \mathrm{KH}_{2} \mathrm{PO}_{4}$, $15.5 \mathrm{mmol} / \mathrm{L} \mathrm{NaHCO}_{3}$, and $11.5 \mathrm{mmol} / \mathrm{L}$ d-glucose) using a tuberculin syringe, and then the basilar artery was frozen in liquid nitrogen and stored at $-80^{\circ} \mathrm{C}$ until use.

2.3. Total RNA Isolation from the Rabbit Basilar Artery. Total RNA was extracted from the basilar artery using the TRIZOL Reagent (Invitrogen, Carlsbad, CA), according to the manufacturer's protocols. The quality of total RNA was evaluated with a spectrophotometer (Nano-Drop2000c; Thermoscientific, Wilmington, DE) and gel electrophoresis (Experion; Bio-Rad, Hercules, CA, USA). RNA samples with an A260/280 ratio higher than 1.8 were used for quantitative real-time polymerase chain reaction (qRT-PCR) analysis. In addition to evaluation with a spectrophotometer, RNA samples with an RNA Quality Index higher than 9.0 were used for gene expression microarray analysis.

2.4. Gene Expression Microarray Analysis of the Rabbit Basilar Artery. Total RNAs extracted from rabbit basilar arteries on days $0,3,5$, and 7 after the first hemorrhage ( $n=3$ each) were used for the microarray analysis. From $50 \mathrm{ng}$ total RNA, cRNA was amplified, labeled, and hybridized to a rabbit gene expression microarray (Agilent Technologies, Santa Clara, CA, USA) using the Low Input Quick Amp one-color Labeling kit (Agilent Technologies) according to the manufacturer's instructions. All hybridized microarray slides were scanned with an Agilent Microarray scanner G2505B (Agilent Technologies). Relative hybridization intensities and background hybridization values were calculated using Agilent Feature Extraction Software (9.5.1.1) (Agilent Technologies). According to the manufacturer's instructions, raw signal intensities and flags for each probe were calculated from hybridization intensities and spot information. The raw signal intensities of the samples were $\log _{2}$ transformed 
and normalized using a quantile algorithm with the "preprocessCore" library package of Bioconductor software [15, 16]. Then, we identified differentially expressed genes in the SAH model using the linear models for microarray analysis (limma) package of Bioconductor software [16, 17]. Genes in SAH samples with a limma value of $P<0.05$ and an absolute limma $\log _{2}$ fold change ( $\mid \log _{2}$ fold change $\left.\mid\right)$ higher than 1.0 compared to the control samples were defined as differentially expressed genes in this study. Microarray data are available from the Gene Expression Omnibus (GEO, http://www.ncbi.nlm.nih.gov/geo/) with the accession number GSE44910.

2.5. Quantitative RT-PCR Analysis of $m R N A$ Expression of RLN1 and RXFP1 in the Rabbit Basilar Artery. Total RNAs extracted from rabbit basilar arteries on days $0,3,5$, and 7 after the first hemorrhage were used for RT-PCR ( $n=5$ each). Complementary DNA (cDNA) was synthesized at $42^{\circ} \mathrm{C}$ for 30 minutes using $200 \mathrm{ng}$ RNA template in a $20 \mu \mathrm{L}$ reaction mixture containing high capacity RNA-to-cDNA master mix (Applied Biosystems, Foster City, CA, USA) with an ABI 2720 thermal cycler (Applied Biosystems). The cDNA was stored at $-80^{\circ} \mathrm{C}$ until use in qRT-PCR. qRT-PCR was performed in triplicate in a $20 \mu \mathrm{L}$ reaction mixture containing TaqMan Fast Universal PCR master mix (Applied Biosystems), $10 \mathrm{ng}$ cDNA, and components of the TaqMan gene expression assay kit (rabbit RLN1: Oc03398001_ml, Applied Biosystems) or Custom TaqMan gene expression assay kit (rabbit $R X F P 1$ : forward primer $5^{\prime}$-GCATTCTCCAGAGAGTGTTTGTCT-3', reverse primer $5^{\prime}$-GGCGCATGCAGATGACAAAA-3', TaqMan probe $5^{\prime}$-ACTGCGGAGACCACC-3', Applied Biosystems) using an ABI 7500 Fast Real-Time PCR system thermal cycler (Applied Biosystems). Glyceraldehyde 3-phosphate dehydrogenase (rabbit GAPDH: Oc03823402_g1) was amplified as an endogenous control. The PCR protocol was composed of initial denaturation at $95^{\circ} \mathrm{C}$ for 20 seconds, followed by 40 amplification cycles of $95^{\circ} \mathrm{C}$ for 3 seconds and $60^{\circ} \mathrm{C}$ for 30 seconds. The data were analyzed with the comparative cycle method. The relative amount $\left(X_{0} / R_{0}\right)$ of target gene mRNA was calculated with the Ct value for the target gene mRNA (CtX) and the Ct value for GAPDH mRNA (CtR) in the same sample using the formula $X_{0} / R_{0}=2^{\mathrm{CtX}-\mathrm{CtR}}$, where $X_{0}$ is the original amount of target gene mRNA and $R_{0}$ is the original amount of GAPDH. The level of target gene expression on day 0 was assigned a value of $100 \%$. The data were expressed as the mean values \pm SEM.

2.6. Enzyme-Linked Immunosorbent Assay (ELISA) Analysis of Relaxin in Rabbit Cerebrospinal Fluid (CSF) and Serum. Rabbit CSF $(n=6)$ and serum $(n=15)$ samples were collected on days $0,3,5$, and 7 . After rabbits were anesthetized and positioned as described above, CSF $(0.5 \mathrm{~mL})$ and arterial blood $(2 \mathrm{~mL})$ were collected from the cisterna magna and central auricular artery, respectively. CSF samples were centrifuged at $10,000 \mathrm{rpm}$ for 5 minutes at $4^{\circ} \mathrm{C}$ to remove red blood cells, nonactivated platelets, and other cellular debris. The supernatant was then frozen at $-80^{\circ} \mathrm{C}$ for later analysis. Rabbit arterial blood $(2 \mathrm{~mL})$ was collected from the rabbit ear artery and transferred into anticoagulant-free vacuum tubes (Venoject VP-AS109 K50, Terumo Corporation, Tokyo, Japan). After centrifugation at $1,500 \times \mathrm{g}$ for 15 minutes at $4^{\circ} \mathrm{C}$, the serum was pipetted into tubes and frozen at $-80^{\circ} \mathrm{C}$ for later analysis. For detection and quantification of the relaxin concentration in rabbit CSF and serum, a commercially available Relaxin ELISA kit (USCN Life Science, Wuhan, China) was used according to the manufacturer's instructions. Standards and all samples were measured in duplicate.

2.7. Perfusion Fixation of the Rabbit Basilar Artery. On days $0,3,5$, and 7 ( $n=3$ each) after the first hemorrhage, rabbits were anesthetized as described above. A thoracotomy was performed, the left ventricle was cannulated with an $18 \mathrm{G}$ catheter (Surflo IV Catheter, Terumo Corporation), the right atrium was opened widely, and the descending thoracic aorta was clamped. Perfusion was begun with $500 \mathrm{~mL}$ heparinized saline $(10 \mathrm{U} / \mathrm{mL})$, followed by $500 \mathrm{~mL} 4.0 \%$ paraformaldehyde through a cannula in the left ventricle with a perfusion pressure of $100 \mathrm{cmH}_{2} \mathrm{O}$. The brain including the basilar artery was removed and stored in $4.0 \%$ paraformaldehyde solution at $4^{\circ} \mathrm{C}$ overnight. For histological examination, the brain including the basilar artery was embedded in paraffin and cut into $6 \mu \mathrm{m}$ sections.

2.8. Immunohistochemical Staining Analysis of RXFP1 Expression in the Rabbit Basilar Artery. The sections were deparaffinized, and endogenous peroxidase activity was quenched by incubation in $3 \% \mathrm{H}_{2} \mathrm{O}_{2}$ in methanol for 30 minutes at room temperature. Heat-induced epitope retrieval was performed at $120^{\circ} \mathrm{C}$ for 20 minutes in $0.01 \mathrm{M}$ citrate buffer. The sections were then incubated with blocking serum (Vectastain Elite ABC kit, Vector Laboratories, Burlingame, CA) followed by incubation with monoclonal anti-mouse LGR7 (RXFP1) antibody (1:100, Sigma-Aldrich, St. Louis, MO, USA) at $4^{\circ} \mathrm{C}$ overnight. Sections were incubated with biotinylated horse anti-mouse antibodies and then incubated with avidinhorseradish peroxidase (HRP) conjugate (Vector Laboratories, Burlingame, CA, USA) according to the manufacturer's recommendations for the Vecstain Elite $\mathrm{ABC}$ kit. The staining procedure was performed using a Vectastain Elite ABC kit (Vector Laboratories) and 3,3'-diaminobenzidine (Dojindo Laboratories, Kumamoto, Japan) according to the manufacturer's instructions. The sections were then counterstained with hematoxylin and observed under a microscope (BZ8000, Keyence, Osaka, Japan). Quantitative analysis was performed by modification of previously described methods [18]. Immunoreactivity was quantitatively analyzed by placing a 25 $\times 25 \mu \mathrm{m}$ square over the most intensely stained area in the tunica media, and densitometric analysis was performed with image analysis software (BZ-Analyzer, Keyence).

2.9. Cell Culture, Treatment, and Protein Extraction. Human brain vascular smooth muscle cells (HBVSMC) were obtained from ScienCell Research Laboratories (Carlsbad, CA, USA) and cultured in smooth muscle cell medium, which consists of $500 \mathrm{~mL}$ basal medium, $10 \mathrm{~mL}$ fetal bovine serum, $5 \mathrm{~mL}$ smooth muscle cell growth supplement, and $5 \mathrm{~mL}$ penicillin/streptomycin solution. Cell cultures were maintained at 
$37^{\circ} \mathrm{C}$ in a humidified atmosphere with $5 \% \mathrm{CO}_{2}$. Cells from passages 5 to 10 were used for the study.

For experiments, cells were seeded at $3-5 \times 10^{5}$ cells $/ 6$ $\mathrm{cm}$ dish and grown until $90 \%$ confluent. Then, cells were incubated in serum-free smooth muscle cell medium (ScienCell Research Laboratories) in the presence or absence of $10 \mathrm{nmol} / \mathrm{L}$ human recombinant relaxin-2 (H2-relaxin, Peprotech, Rocky Hill, NJ, USA) for 24 hours. After stimulation with $100 \mathrm{nmol} / \mathrm{L}$ endothelin-1 (Peptide Institute, Osaka, Japan) for $0,5,10$, and 30 minutes with or without relaxin treatment, smooth muscle cell proteins were extracted as follows.

At the indicated time points, cells were rinsed three times with ice-cold phosphate-buffered saline (PBS: $136.9 \mathrm{mmol} / \mathrm{L}$ $\mathrm{NaCl}, 2.7 \mathrm{mmol} / \mathrm{L} \mathrm{KCl}, 8.1 \mathrm{mmol} / \mathrm{L} \mathrm{Na}_{2} \mathrm{HPO}_{4} 12 \mathrm{H}_{2} \mathrm{O}$, and $1.47 \mathrm{mmol} / \mathrm{L} \mathrm{KH}_{2} \mathrm{PO}_{4}$ ) and lysed with ice-cold cell lysis buffer (50 mmol/L HEPES, pH 7.4, $150 \mathrm{mmol} / \mathrm{L} \mathrm{NaCl}, 0.5 \%$ (v/v) Nonidet P-40, and $5 \mu \mathrm{mol} / \mathrm{L}$ microcystin-LR). Immediately after scraping the cells off the dishes, cell lysates were snapfrozen in liquid nitrogen and thawed at room temperature. After centrifugation for 15 minutes at $12,000 \mathrm{rpm}$ at $4^{\circ} \mathrm{C}$, the supernatants were collected. The protein concentrations of the supernatants were measured using the Bradford method (Thermo Fisher Scientific, Waltham, MA, USA). The samples were diluted to a final concentration of $1 \mathrm{mg} / \mathrm{mL}$ with the cell lysis buffer and $4 \times$ LDS NuPAGE sample buffer (Invitrogen) and stored at $-80^{\circ} \mathrm{C}$ until use.

2.10. Analysis of Myosin Light Chain (MLC) Phosphorylation with Phos-Tag Sodium Dodecyl Sulfate-Polyacrylamide Gel Electrophoresis (SDS-PAGE). Phosphorylation of MLC was analyzed using a new method based on Phos-tag technology. Phos-tag is a compound that specifically binds to phosphate groups. Therefore, SDS-PAGE containing polyacrylamidebound $\mathrm{Mn}^{2+}$ Phos-tag (Phos-tag SDS-PAGE) causes a mobility shift, depending on the degree of phosphorylation [19].

Before electrophoresis, the samples were heated at $100^{\circ} \mathrm{C}$ for 5 minutes and equilibrated to room temperature. The $2 \mu \mathrm{g}$ protein samples were separated on $12.5 \%(\mathrm{w} / \mathrm{v})$ polyacrylamide gels containing $30 \mu \mathrm{M}$ Phos-tag Acrylamide (NARD Institute, Hyogo, Japan) for SDS-PAGE and transferred to polyvinylidene difluoride membranes (Bio-Rad). Electrophoresis was performed in $0.1 \%$ (w/v) SDS, $25 \mathrm{mmol} / \mathrm{L}$ Tris-hydroxymethyl aminomethane, and $192 \mathrm{mmol} / \mathrm{L}$ glycine at $12 \mathrm{~mA}$ constant current $/ 8 \mathrm{~cm} \times 5 \mathrm{~cm} \times 0.75 \mathrm{~mm}$ gel for 155 minutes. After electrophoresis, the gel was soaked for 30 minutes in transfer buffer $(25 \mathrm{mmol} / \mathrm{L}$ Tris, $192 \mathrm{mmol} / \mathrm{L}$ glycine, and $10 \%(\mathrm{v} / \mathrm{v})$ methanol) containing $2 \mathrm{mmol} / \mathrm{L}$ EDTA to remove the $\mathrm{Mn}^{2+}$ and then in transfer buffer without EDTA for 15 minutes. Proteins were then transferred to polyvinylidene difluoride membranes $(0.2 \mu \mathrm{m}$ pore size; Bio$\mathrm{Rad}$ ) in transfer buffer for 2 hours at room temperature. The membranes were then washed in PBS for 5 minutes and treated with $0.5 \%(\mathrm{w} / \mathrm{v})$ formaldehyde in PBS for 45 minutes. After a brief wash in PBS, the membrane was blocked with $5 \%(\mathrm{w} / \mathrm{v})$ skimmed milk in T-TBS overnight at $4^{\circ} \mathrm{C}$. All forms of $20 \mathrm{kDa}$ MLCs were detected on the immunoblot using a rabbit polyclonal anti-MLC antibody (1:500; Santa Cruz Biotechnology, Santa Cruz, CA, USA) and

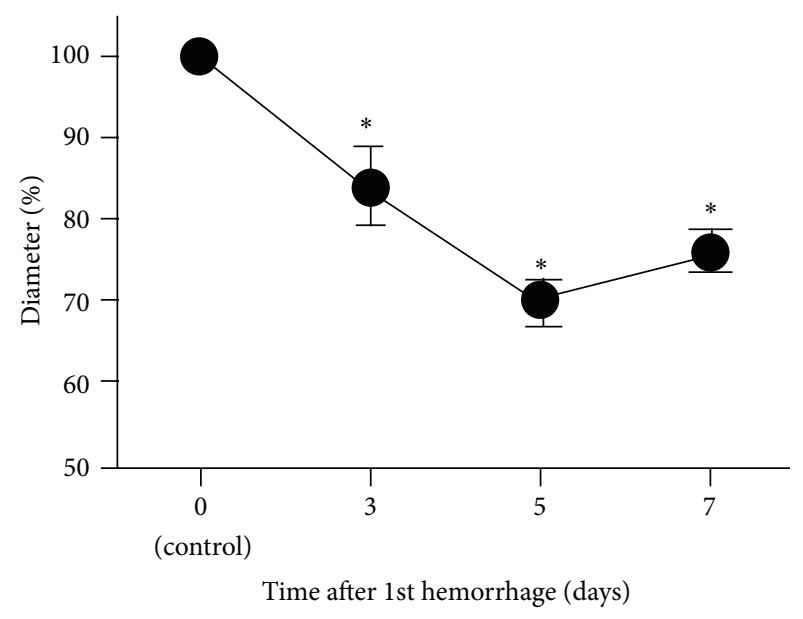

FIGURE 1: Time course of narrowing of the rabbit basilar artery after subarachnoid hemorrhage (SAH). Time course of changes in the external diameter of rabbit basilar arteries after SAH. Data are the means $\pm \operatorname{SEM}(n=3$, each time point). The external diameter on day 0 was considered $100 \% .{ }^{*} P<0.05$ versus day 0 (control).

horseradish peroxidase-conjugated goat anti-rabbit IgG antibody (1:1000; Sigma) diluted in immunoreaction enhancer solution (Can Get Signal; Toyobo, Osaka, Japan). The immune complex was detected using enhanced chemiluminescence (ECL plus kit; Amersham, Buckinghamshire, UK). The light emission was detected and analyzed with VersaDoc 5000 and the computer program Quantity One (Bio-Rad). The percent of phosphorylated MLC of the total MLC (sum of unphosphorylated and phosphorylated forms) was calculated to indicate the extent of MLC phosphorylation.

2.11. Statistical Analysis. The data are expressed as the mean value \pm SEM of the indicated experimental number. One basilar arterial preparation obtained from one animal was used for each experiment, and therefore the number of experiments ( $n$ value) equals the number of rabbits. An analysis of variance followed by Dunnett's post hoc test was used to determine statistically significant differences in a multiple comparison with the control model. A value of $P<0.05$ was considered statistically significant. All analyses were performed using GraphPad PRISM software version 5.0 (GraphPad software, San Diego, CA, USA).

\section{Results}

3.1. Assessment of Cerebral Vasospasm following SAH. The external diameter of the basilar artery was $0.87 \pm 0.048 \mathrm{~mm}$ in the controls (day 0, before SAH induction). On day 3, the basilar artery was significantly narrowed to $84.0 \pm 4.7 \%$ of the control $(P<0.05)$. The basilar arterial narrowing peaked on day $5(70.1 \pm 2.8 \%$ of the control, $P<0.05)$ and then persisted to day $7(76.1 \pm 2.6 \%$ of the control, $P<0.05)$ (Figure 1$)$.

3.2. $m R N A$ Expression of RLN1 and RXFP1 in the Rabbit Basilar Artery after SAH and Microarray Analysis of the Rabbit Basilar Artery. The three most significantly upregulated 
TABLE 1: The top three most highly upregulated genes in the rabbit basilar artery after subarachnoid hemorrhage identified with microarray analysis.

\begin{tabular}{ccccccc}
\hline & \multicolumn{2}{c}{ Day 3 } & \multicolumn{2}{c}{ Day 5} & \multicolumn{2}{c}{ Day 7 } \\
& Gene & $\log _{2} \mathrm{FC}$ & Gene & $\log _{2} \mathrm{FC}$ & Gene & $\log _{2} \mathrm{FC}$ \\
\hline 1 & SAA & 6.02 & RLN1 & 4.73 & RLN1 & 4.82 \\
2 & SAA3P & 5.88 & SAA3P & 3.50 & SAA3P & 3.93 \\
3 & HP & 5.78 & HP & 3.40 & HP & 3.47 \\
\hline
\end{tabular}

SAA: serum amyloid A; SAA3P: serum amyloid A3 protein; HP: haptoglobin; RLN1: relaxin-1; $\log _{2}$ FC: $\log _{2}$ fold change.

genes in the rabbit basilar artery after SAH on days 3, 5, and 7 compared to day 0 were identified from our previous microarray data (GEO accession number GSE44910) and are listed in Table 1 [20]. Among all investigated differentially expressed genes, RLN1 was the most upregulated gene on days 5 and 7. The $\log _{2}$ fold changes for RLN1 were 2.1, 4.7, and 4.8 on days 3,5 , and 7 , respectively. We focused on $R L N 1$ for further investigation because the RLN1 mRNA was markedly upregulated on days 5 and 7 when delayed cerebral vasospasm became more severe. To confirm the RLN1 mRNA expression seen in the microarray, qRT-PCR was performed and showed that the expression of RLN1 mRNA was significantly upregulated on day 7 compared to day 0 (Figure 2(a)). Next, we investigated the expression of RXFP1, which is a specific receptor for $R L N 1$ that is not present on the microarray chip we used. Quantitative RT-PCR revealed that RXFP1 mRNA was significantly downregulated on days 3 and 7 (Figure 2(b)). RLN1 mRNA was gradually upregulated after $\mathrm{SAH}$, whereas RXFP1 mRNA was persistently downregulated immediately after SAH.

\subsection{Time Course of Changes in the Relaxin Concentration} in CSF and Serum in Rabbits after SAH. We performed ELISA to measure the relaxin concentration in the rabbit CSF and serum after SAH. Before SAH induction, the relaxin concentration in CSF was $16.5 \pm 5.6 \mathrm{pg} / \mathrm{mL}$. After SAH, the relaxin concentration in CSF increased gradually and peaked on day 7. The relaxin concentrations in CSF on days 3, 5, and 7 were $27.9 \pm 11.8 \mathrm{pg} / \mathrm{mL}, 58.3 \pm 6.9 \mathrm{pg} / \mathrm{mL}$, and $79.9 \pm$ $15.9 \mathrm{pg} / \mathrm{mL}$, respectively, with significant elevation on days 5 and 7 (Figure 3(a)). The time course of elevation of the relaxin concentration in CSF was consistent with the upregulation of RLN1 mRNA in the basilar artery.

The relaxin concentration in serum was $161.5 \pm$ $29.1 \mathrm{pg} / \mathrm{mL}$ before induction of $\mathrm{SAH}$, and on days 3, 5 , and 7 , the concentrations were $219.5 \pm 38.7 \mathrm{pg} / \mathrm{mL}$, $237.5 \pm 40.6 \mathrm{pg} / \mathrm{mL}$, and $233.9 \pm 46.7 \mathrm{pg} / \mathrm{mL}$, respectively. No significant difference was found between control and $\mathrm{SAH}$ samples at any time (Figure 3(b)).

3.4. Localization and Expression of RXFP1 in the Rabbit Basilar Artery. To assess the localization of RXFP1 expression in the rabbit basilar artery, immunohistochemical analysis of RXFP1 was performed. RXFP1-positive cells were observed in all layers of the rabbit basilar artery, especially in the media tunica of both control (day 0) and SAH (days 3, 5, and 7) samples (Figure 4(a)). Immunoreactivity for RXFP1 was seen on day 0 , indicating that RXFP1 was constitutively expressed in normal basilar arteries of rabbits.

Densitometry demonstrated that RXFP1 immunoreactivity on days 3,5, and 7 was significantly decreased compared to day 0 . Arbitrary densitometric units for each day were as follows: $1,008,818.6 \pm 60,874.8$ on day $0,489,367.1 \pm 139,762.8$ on day $3(P<0.05), 359,591.3 \pm 76,946.9$ on day $5(P<0.05)$, and $427,643.9 \pm 147,666.8$ on day $7(P<0.05)$ (Figure $4(\mathrm{~b})$ ). The time course of RXFP1 immunoreactivity was consistent with that of RXFP1 mRNA expression.

3.5. Phosphorylation of MLCs during Endothelin-1 Stimulation of Cultured HBVSMC. Phos-tag SDS-PAGE followed by immunoblot detection with anti-MLC antibody yielded three bands, as previously reported [21]. The upper, middle, and lower bands were di-, mono-, and nonphosphorylated forms of MLC, respectively. HBVSMC contained $71.0 \pm 3.5 \%$ monoand di-phosphorylated forms of MLC before endothelin-1 stimulation $(n=3)$.

HBVSMC preincubated with relaxin contained $68.9 \pm$ $3.2 \%$ phosphorylated MLC before endothelin-1 stimulation $(n=3)$. No significant difference in the resting level of MLC phosphorylation (the sum of di- and mono-phosphorylation) was found between HBVSMC preincubated with or without relaxin. Endothelin-1 (100 nmol/L) significantly increased the level of MLC phosphorylation in HBVSMC preincubated with $(82.1 \pm 1.6 \%, P<0.05)$ and without $(80.4 \pm 1.4 \%$, $P<0.05)$ relaxin 5 minutes after stimulation $(n=3)$. Ten minutes after endothelin-1 stimulation, the level of MLC phosphorylation was still significantly elevated in HBVSMC not preincubated with relaxin $(79.5 \pm 1.3 \%, P<0.05)$, whereas it declined in HBVSMC preincubated with relaxin $(78.7 \pm 1.1 \%, P>0.05)(n=3)$. Then, the level of MLC phosphorylation declined in HBVSMC preincubated both with $(72.9 \pm 3.7 \%, P>0.05)$ and without $(75.4 \pm 1.0 \%$, $P>0.05)$ relaxin 30 minutes after endothelin-1 stimulation $(n=3)$ (Figure 5).

\section{Discussion}

In this study, we demonstrated that relaxin and RXFP1 are expressed in the rabbit basilar artery and that their expression was altered after SAH. RLN1 mRNA was gradually upregulated after $\mathrm{SAH}$, whereas RXFP1 mRNA and protein were downregulated just after SAH. Moreover, the relaxin concentration in CSF was elevated after SAH, and the time course of elevation of relaxin in CSF was consistent with the progression of cerebral vasospasm. We also demonstrated that pretreatment with human recombinant relaxin-2 reduced the sustained MLC phosphorylation that was caused by endothelin-1 stimulation in HBVSMC, suggesting that relaxin inhibits the endothelin-1-induced sustained contraction in the cerebral arteries. These data suggest that upregulation of relaxin-1 and downregulation of RXFP1 play an important role in the development of cerebral vasospasm.

Relaxin affects several organs and exerts multiple effects including vasodilatation, antifibrosis, and anti-inflammation, 


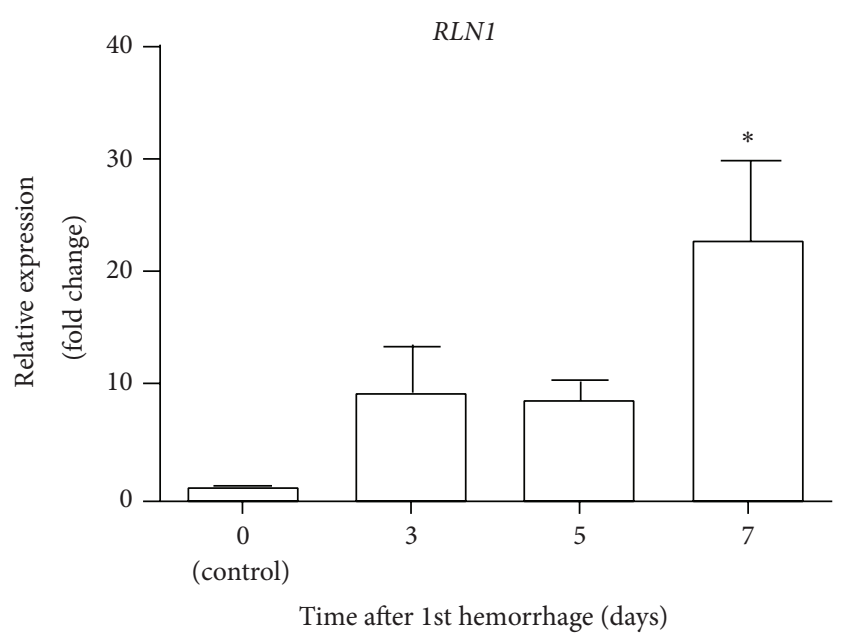

(a)

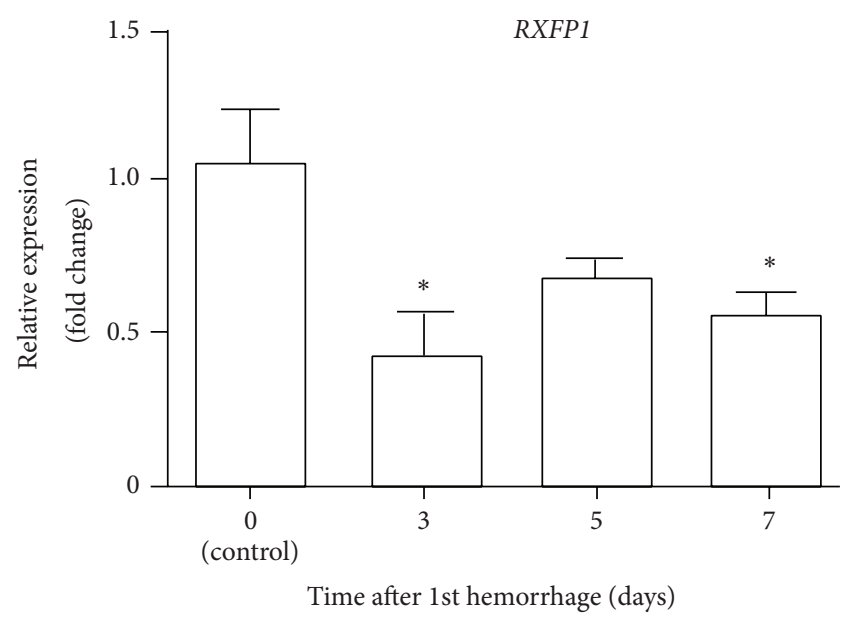

(b)

FIGURE 2: Time course of changes in mRNA expression of RLN1 and RXFP1 in the rabbit basilar artery after subarachnoid hemorrhage (SAH). Quantitative real-time polymerase chain reaction analysis of RLN1 (a) and RXFP1 (b) mRNA expression in the basilar artery after SAH. Data are the means $\pm \operatorname{SEM}(n=5)$. The level of mRNA expression on day 0 was considered $1.0 .{ }^{*} P<0.05$ versus day 0 (control).

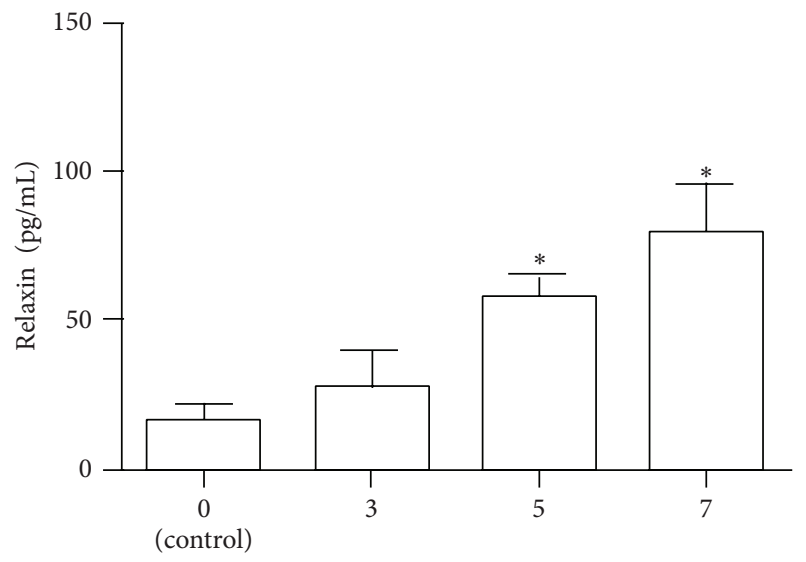

Time after 1st hemorrhage (days)

(a)

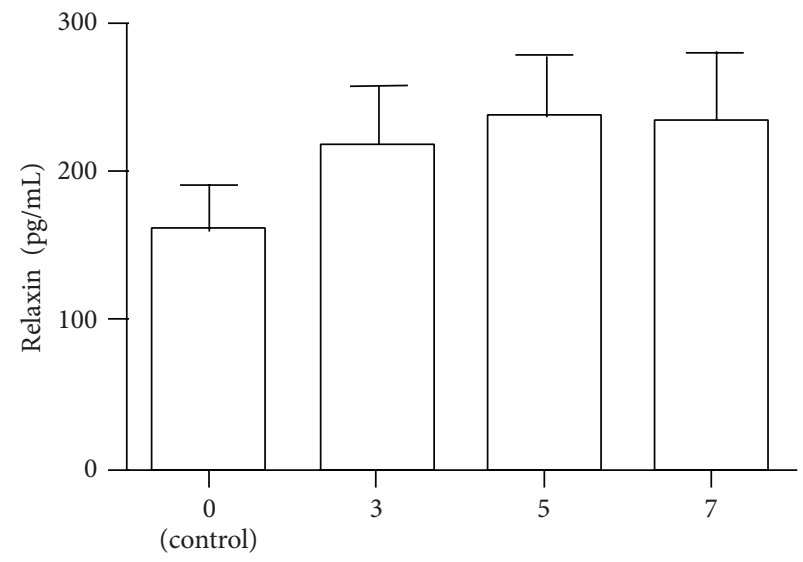

Time after 1st hemorrhage (days)

(b)

FIGURE 3: Time course of changes in the concentration of relaxin in cerebrospinal fluid (CSF) and serum in rabbits after subarachnoid hemorrhage (SAH). Enzyme-linked immunosorbent assay analysis of the relaxin concentration in the CSF (a) and serum (b) of rabbits after SAH. Data are the means $\pm \operatorname{SEM}(\operatorname{CSF} n=6$, $\operatorname{serum} n=15) .{ }^{*} P<0.05$ versus day 0 (control).

and this peptide maintains organ blood flow via RXFP1 $[8,14,22]$. Several studies have demonstrated that relaxin dilates arteries $[23,24]$. Our in vitro data demonstrated that relaxin reduced the sustained MLC phosphorylation after endothelin-1 stimulation. Therefore, relaxin has the potential to dilate cerebral arteries. Immunohistochemistry and qRTPCR demonstrated that downregulation of RXFP1 occurred 3 days after SAH and persisted to day 7 in the rabbit basilar artery. A previous study in rats reported that downregulation of RXFP1 expression in the uterus reduces the smooth muscle relaxation activity of relaxin [25]. Therefore, the vasodilatory effect of relaxin on cerebral arteries may be reduced in the rabbit basilar artery after SAH. A functional decrease in relaxin activity caused by RXFP1 downregulation seems to be involved in the development of cerebral vasospasm. Because relaxin exerts multiple effects on several organs, further studies are needed to elucidate the effects of relaxin on cerebral arteries.

The mechanism of regulation of RXFP1 expression in the artery remains unknown. Expression of RLN3 mRNA may contribute to the mechanism of RXFP1 downregulation in rat heart [6]. In this study, RLN3 mRNA was not detected in the rabbit basilar artery at any time point investigated (data not shown). Moore et al. proposed that $\beta$-adrenergic receptor activation, especially $\beta 1$-adrenergic receptors, suppresses the expression of RXFP1 mRNA in rat heart [26]. Adrenaline is a representative spasmogen [1] and is increased in plasma and CSF after SAH [27]. The elevated expression of adrenaline 

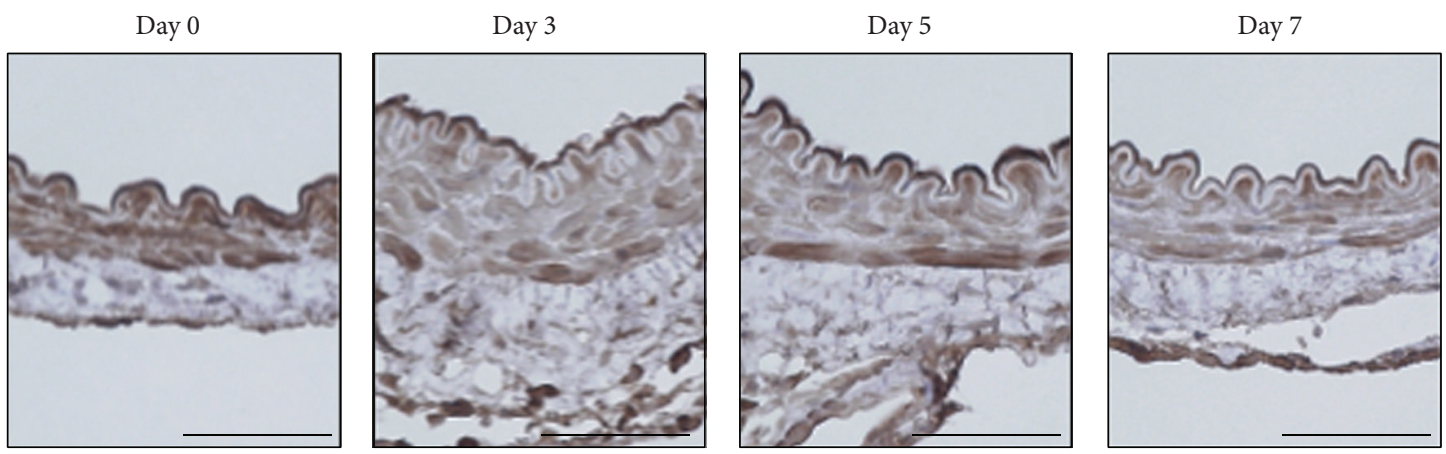

(a)

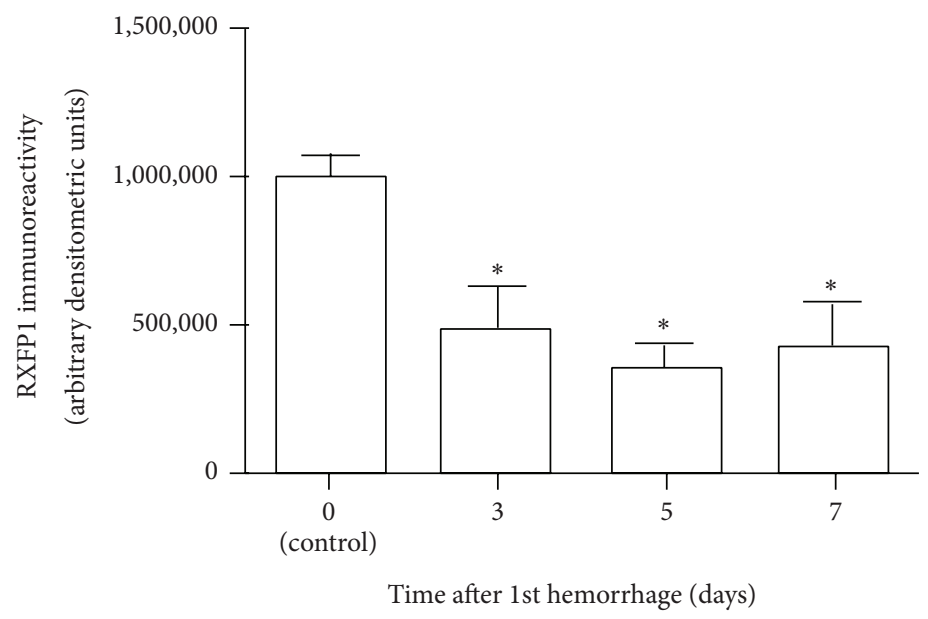

(b)

FIGURE 4: Time course of changes in RXFP1 expression in the rabbit basilar artery after subarachnoid hemorrhage (SAH). (a) Representative images of immunohistochemical staining for RXFP1 on cross sections of rabbit basilar arteries after SAH (scale bars, $50 \mu \mathrm{m}$ ). (b) A summary of densitometric analysis of immunohistochemical staining for RXFP1. Data are the means \pm SEM $\left(n=3\right.$ per group). ${ }^{*} P<0.05$ versus day 0 (control).

may participate in the mechanism of RXFP1 downregulation in the basilar arteries after SAH.

Luteral relaxin expression is regulated by luteinizing hormone, chorionic gonadotrophin, and basic fibroblast growth factor [28]. However, the mechanism of regulation of the expression of arterial-derived relaxin remains elusive. Our data demonstrated that downregulation of RXFP1 was followed by upregulation of relaxin-1. One explanation for this finding may be that a receptor-ligand feedback mechanism exists to regulate the expression of the ligand. However, further research is needed to identify the mechanism of regulation of expression of relaxin-1 and RXFP1 in the cerebral arteries after SAH.

The concentration of relaxin in CSF was significantly elevated after SAH, and the time course was consistent with that of RLN1 mRNA expression in the rabbit basilar artery. In contrast, the relaxin concentration in serum was not elevated after SAH. The relaxin concentration in serum is affected by systemic conditions such as pregnancy, heart failure, and cancer $[3,29,30]$. The relaxin concentration in CSF may be affected by intracranial conditions after SAH. Arterial-derived relaxin is produced locally and acts in an autocrine/paracrine manner $[8,13]$. Therefore, the elevated relaxin concentration in CSF indicates that relaxin is produced in the basilar arterial wall and secreted into the CSF. Furthermore, the time course of the relaxin concentration in CSF was correlated with the progression of cerebral vasospasm after SAH. Thus, the relaxin concentration in CSF may be a potential biomarker for detecting the presence of cerebral vasospasm after SAH.

In conclusion, we demonstrated that $R L N 1$ mRNA was gradually upregulated after SAH, whereas RXFP1 mRNA and protein were downregulated just after SAH. The relaxin concentration in CSF was significantly elevated after SAH, and the time course was consistent with that of expression of RLN1 mRNA in the rabbit basilar artery. These findings suggest that expression and signaling of relaxin and RXFP1 participate in the development of cerebral vasospasm after SAH. Moreover, downregulation of RXFP1 may cause a functional reduction in relaxin activity in cerebral arteries during vasospasm. Further studies are needed to clarify the role of relaxin in the development of cerebral vasospasm.

\section{Conflict of Interests}

The authors declare that they have no conflict of interests. 


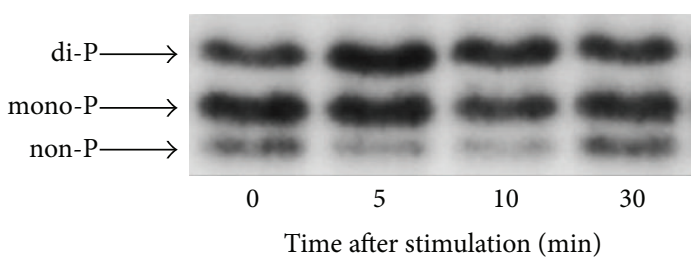

(a)

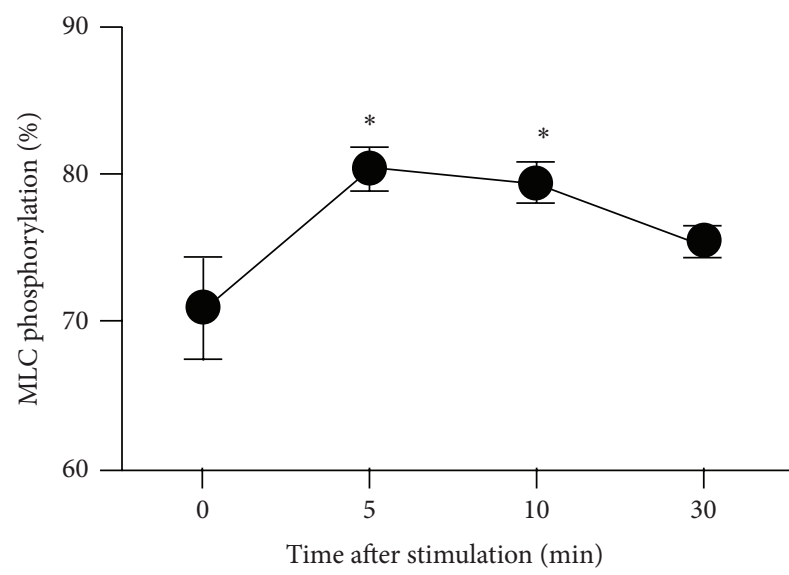

(c)

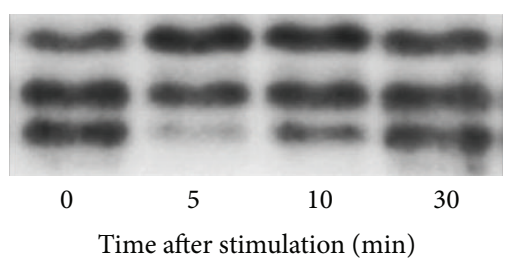

(b)

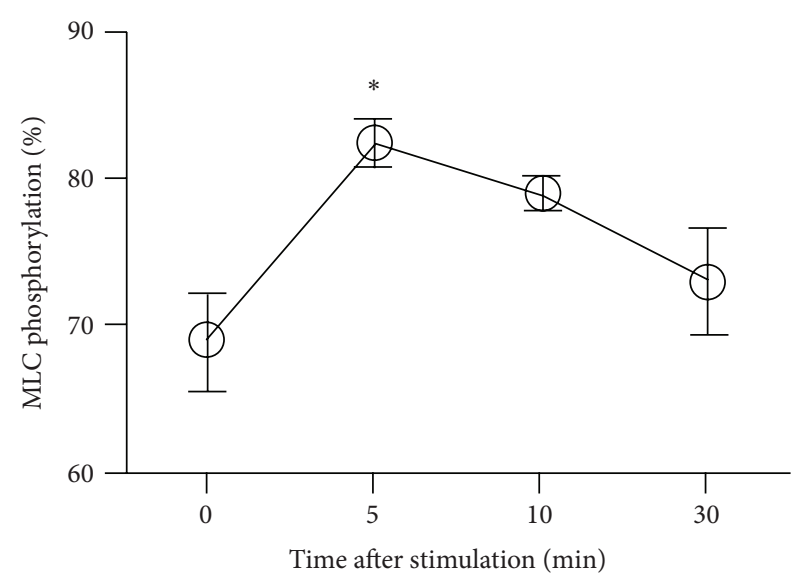

(d)

FIGURE 5: Time course of changes in myosin light chain (MLC) phosphorylation induced by endothelin-1 in human brain vascular smooth muscle cells (HBVSMC). Representative immunoblot analysis of MLC phosphorylation in HBVSMC preincubated without (a) and with (b) human recombinant relaxin-2 (H2 relaxin). The upper, middle, and lower bands detected with anti-MLC antibody represented di-, mono, and nonphosphorylated forms of MLC, respectively. Summary of the level of MLC phosphorylation (percent of total MLC) induced by $100 \mathrm{nmol} / \mathrm{L}$ endothelin-1 at four time points: just before relaxin stimulation ( 0 minutes) and 5, 10, and 30 minutes after relaxin stimulation ((c) preincubated without $\mathrm{H} 2$ relaxin, (d) preincubated with $\mathrm{H} 2$ relaxin). The data are the means $\pm \operatorname{SEM}(n=3)$. ${ }^{*} P<0.05$ versus 0 minutes.

\section{Acknowledgment}

This research was supported by JSPS KAKENHI Grant nos. 22249054,24791510 , and 26462164.

\section{References}

[1] N. F. Kassell, T. Sasaki, A. R. T. Colohan, and G. Nazar, “Cerebral vasospasm following aneurysmal subarachnoid hemorrhage," Stroke, vol. 16, no. 4, pp. 562-572, 1985.

[2] X. Wang, Y. M. Li, W. Q. Li, C. G. Huang, Y. C. Lu, and L. J. Hou, "Effect of clazosentan in patients with aneurysmal subarachnoid hemorrhage: a meta-analysis of randomized controlled trials," PLoS ONE, vol. 7, no. 10, Article ID e47778, 2012.

[3] D. Bani, "Relaxin: a pleiotropic hormone," General Pharmacology, vol. 28, no. 1, pp. 13-22, 1997.

[4] O. D. Sherwood, "Relaxin's physiological roles and other diverse actions," Endocrine Reviews, vol. 25, no. 2, pp. 205-234, 2004.

[5] T. N. Wilkinson, T. P. Speed, G. W. Tregear, and R. A. D. Bathgate, "Evolution of the relaxin-like peptide family," BMC Evolutionary Biology, vol. 5, article 14, 2005.

[6] A. R. Kompa, C. S. Samuel, and R. J. Summers, "Inotropic responses to human gene 2 (B29) relaxin in a rat model of myocardial infarction (MI): effect of pertussis toxin," The British Journal of Pharmacology, vol. 137, no. 5, pp. 710-718, 2002.

[7] C. S. Samuel, X. Du, R. A. D. Bathgate, and R. J. Summers, "Relaxin' the stiffened heart and arteries: the therapeutic potential for relaxin in the treatment of cardiovascular disease," Pharmacology and Therapeutics, vol. 112, no. 2, pp. 529-552, 2006.

[8] R. A. D. Bathgate, M. L. Halls, E. T. van der Westhuizen, G. E. Callander, M. Kocan, and R. J. Summers, "Relaxin family peptides and their receptors," Physiological Reviews, vol. 93, no. 1, pp. 405-480, 2013.

[9] R. A. Bathgate, R. Ivell, B. M. Sanborn, O. D. Sherwood, and R. J. Summers, "International union of pharmacology LVII: recommendations for the nomenclature of receptors for relaxin family peptides," Pharmacological Reviews, vol. 58, no. 1, pp. 731, 2006.

[10] S. Y. Hsu, K. Nakabayashi, S. Nishi et al., "Activation of orphan receptors by the hormone relaxin," Science, vol. 295, no. 5555, pp. 671-674, 2002.

[11] K. P. Conrad and J. Novak, "Emerging role of relaxin in renal and cardiovascular function," The American Journal of Physiology-Regulatory Integrative and Comparative Physiology, vol. 287, no. 2, pp. R250-R261, 2004.

[12] D. Bani, "Relaxin as a natural agent for vascular health," Vascular Health and Risk Management, vol. 4, no. 3, pp. 515-524, 2008.

[13] J. Novak, L. J. Parry, J. E. Matthews et al., "Evidence for local relaxin ligand-receptor expression and function in arteries," The FASEB Journal, vol. 20, no. 13, pp. 2352-2362, 2006.

[14] L. A. Vodstrcil, M. Tare, J. Novak et al., "Relaxin mediates uterine artery compliance during pregnancy and increases 
uterine blood flow," The FASEB Journal, vol. 26, no. 10, pp. 40354044, 2012.

[15] B. M. Bolstad, R. A. Irizarry, M. Åstrand, and T. P. Speed, "A comparison of normalization methods for high density oligonucleotide array data based on variance and bias," Bioinformatics, vol. 19, no. 2, pp. 185-193, 2003.

[16] R. C. Gentleman, V. J. Carey, D. M. Bates et al., "Bioconductor: open software development for computational biology and bioinformatics," Genome Biology, vol. 5, article R80, no. 10, 2004.

[17] R. C. Gentleman, V. Carey, W. Hüber, R. Irizarry, and R. Dudoit, Bioinformatics and Computational Biology Solutions Using R and Bioconductor, Springer, New York, NY, USA, 2005.

[18] M. Yamaguchi-Okada, S. Nishizawa, M. Koide, and Y. Nonaka, "Biomechanical and phenotypic changes in the vasospastic canine basilar artery after subarachnoid hemorrhage," Journal of Applied Physiology, vol. 99, no. 5, pp. 2045-2052, 2005.

[19] K. Takeya, K. Loutzenhiser, M. Shiraishi, R. Loutzenhiser, and M. P. Walsh, "A highly sensitive technique to measure myosin regulatory light chain phosphorylation: the first quantification in renal arterioles," American Journal of Physiology-Renal Physiology, vol. 294, no. 6, pp. F1487-F1492, 2008.

[20] S. Matsuo, Y. Kikkawa, M. Hokama et al., "Gene expression profiling and bioinformatic analysis of rabbit Basilar artery after experimental subarachnoid hemorrhage," Journal of Neurology and Neurophysiology, 2014.

[21] Y. Kikkawa, K. Kameda, M. Hirano, T. Sasaki, and K. Hirano, "Impaired feedback regulation of the receptor activity and the myofilament $\mathrm{Ca}^{2+}$ sensitivity contributes to increased vascular reactiveness after subarachnoid hemorrhage," Journal of Cerebral Blood Flow \& Metabolism, vol. 30, no. 9, pp. 1637-1650, 2010.

[22] J. M. Willcox, A. J. S. Summerlee, and C. L. Murrant, "Relaxin induces rapid, transient vasodilation in the microcirculation of hamster skeletal muscle," Journal of Endocrinology, vol. 218, no. 2, pp. 179-191, 2013.

[23] C. Fisher, M. MacLean, I. Morecroft et al., "Is the pregnancy hormone relaxin also a vasodilator peptide secreted by the heart?" Circulation, vol. 106, no. 3, pp. 292-295, 2002.

[24] Y. Li, Z. L. S. Brookes, and S. Kaufman, "Acute and chronic effects of relaxin on vasoactivity, myogenic reactivity and compliance of the rat mesenteric arterial and venous vasculature," Regulatory Peptides, vol. 132, no. 1-3, pp. 41-46, 2005.

[25] L. A. Vodstrcil, O. Shynlova, J. W. Verlander, M. E. Wlodek, and L. J. Parry, "Decreased expression of the rat myometrial relaxin receptor (RXFP1) in late pregnancy is partially Mediated by the Presence of the conceptus," Biology of Reproduction, vol. 83, no. 5, pp. 818-824, 2010.

[26] X. L. Moore, A. Hong, and X. J. Du, " $\alpha 1$-Adrenergic activation upregulates expression of relaxin receptor RXFP1 in cardiomyocytes," Annals of the New York Academy of Sciences, vol. 1160, pp. 285-286, 2009.

[27] A. Dilraj, J. H. Botha, V. Rambiritch, R. Miller, and J. R. van Dellen, "Levels of catecholamine in plasma and cerebrospinal fluid in aneurysmal subarachnoid hemorrhage," Neurosurgery, vol. 31, no. 1, pp. 42-51, 1992.

[28] T. Dschietzig, C. Bartsch, G. Baumann, and K. Stangl, "Relaxina pleiotropic hormone and its emerging role for experimental and clinical therapeutics," Pharmacology and Therapeutics, vol. 112, no. 1, pp. 38-56, 2006.

[29] P. Ren, Z. Yu, L. Xiu, M. Wang, and H. Liu, "Elevated serum levels of human relaxin-2 in patients with esophageal squamous cell carcinoma," World Journal of Gastroenterology, vol. 19, no. 15, pp. 2412-2418, 2013.
[30] T. Dschietzig, C. Richter, C. Bartsch et al., "The pregnancy hormone relaxin is a player in human heart failure," The FASEB Journal, vol. 15, no. 12, pp. 2187-2195, 2001. 


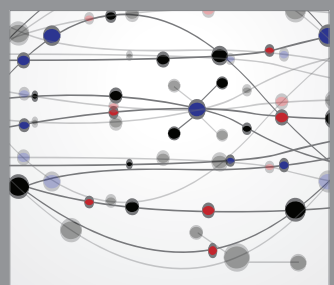

The Scientific World Journal
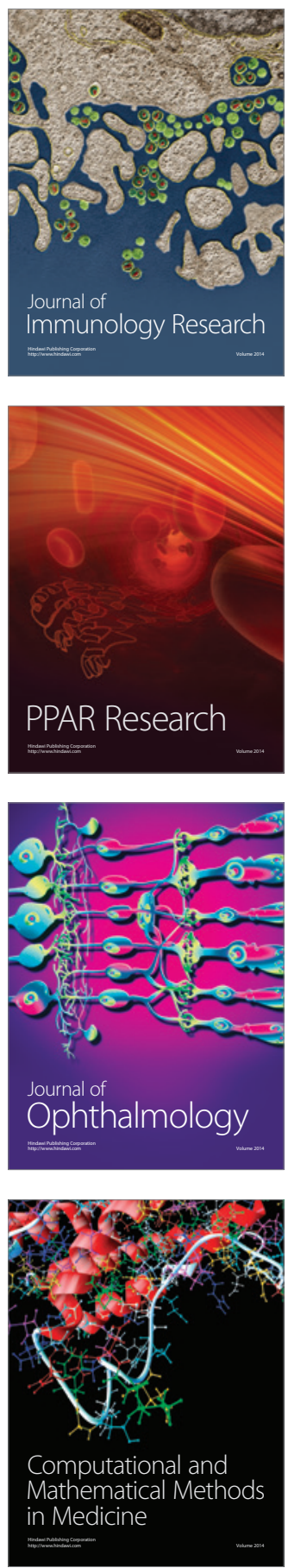

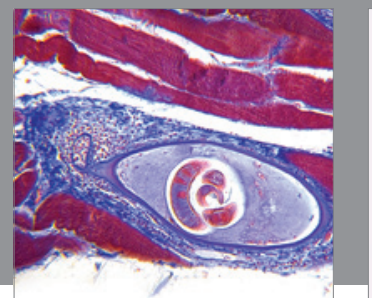

Gastroenterology

Research and Practice
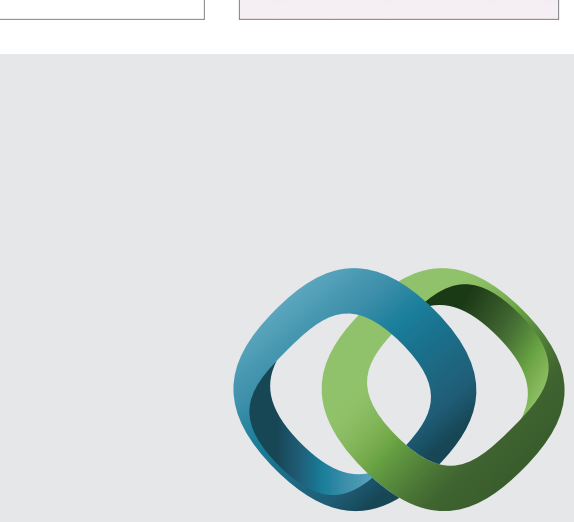

\section{Hindawi}

Submit your manuscripts at

http://www.hindawi.com
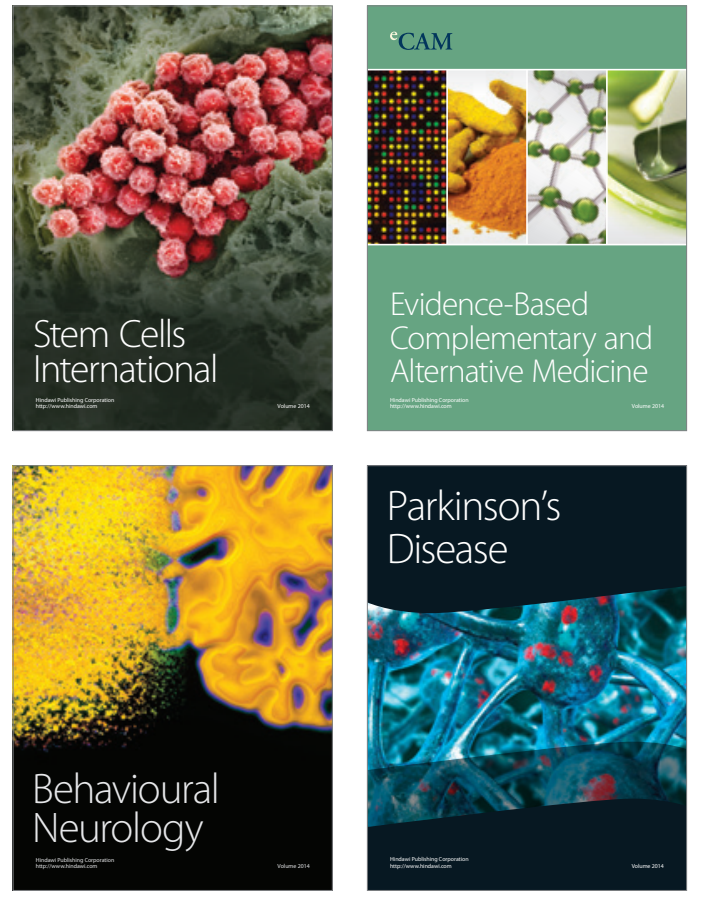
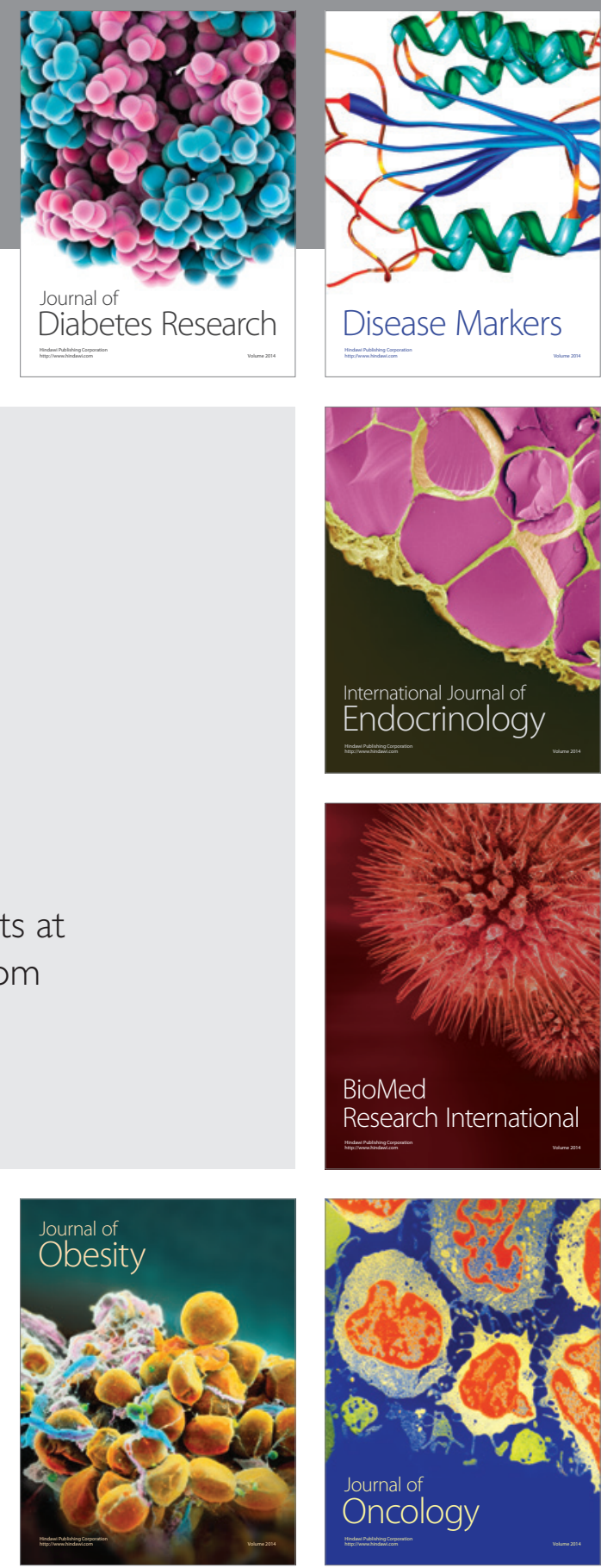

Disease Markers
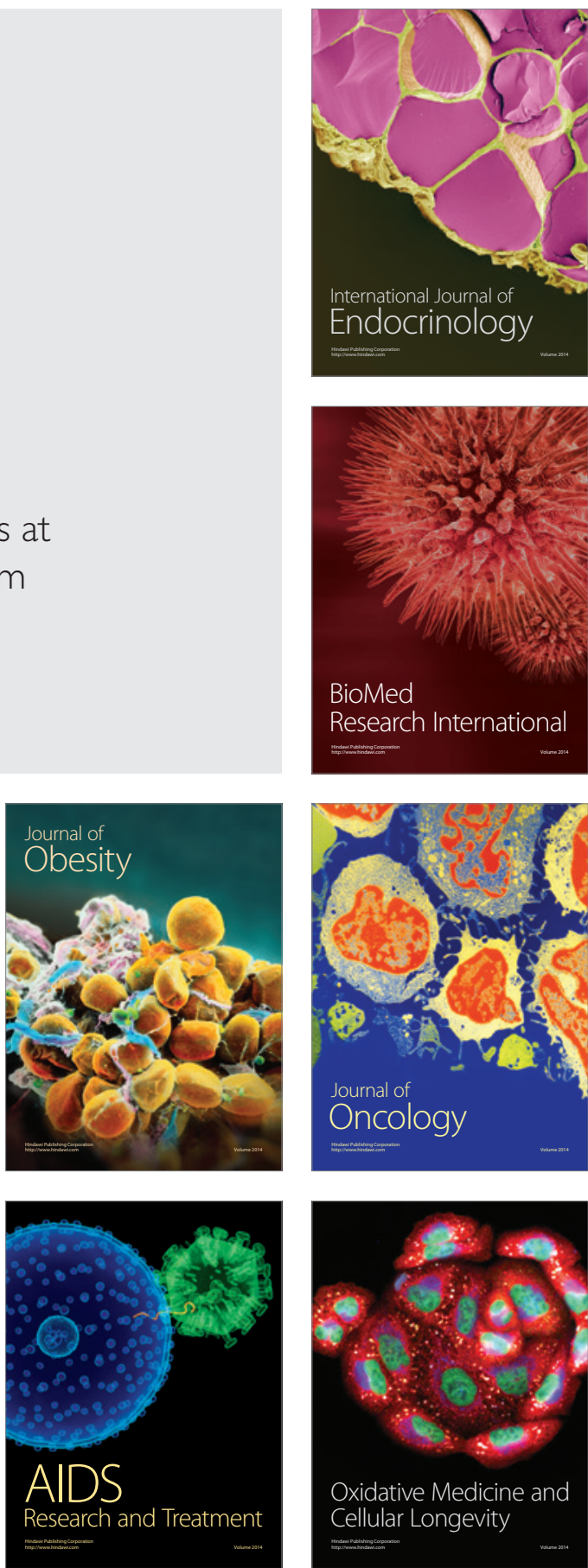